ISSN: 2448-0657

periodicos.ufsm.br/refilo

Universidade Federal de Santa Maria/UFSM Santa Maria, RS, Brasil

\title{
TEORIA FEMINISTA E ENSINO DE FILOSOFIA
}

\author{
FEMINIST THEORY AND TEACHING OF PHILOSOPHY
}

Fernanda Gabriela Soares dos Santos'

\begin{abstract}
Resumo: $O$ trabalho a seguir é uma introdução à teoria feminista, na medida em que foi idealizado para uma aula de qualquer um dos anos do Ensino Médio. O objetivo é iniciar as alunas e alunos nos estudos sobre Epistemologia e seus objetos, bem como problematizar a presença das mulheres nas pesquisas Epistemológicas. Desde os primórdios cientíícos, quem foram os cânones da Ciência? Onde elas estavam? Colocados tais questionamentos, o segundo momento é apresentar aos educandos algumas inquietações sobre a ausência das mulheres na Epistemologia.
\end{abstract}

Palavras-chave: Ausência; Mulheres; Teoria.

\begin{abstract}
The following work is an introduction to the feminist theory, in that it was idealized for a class in any of the high school years. The objective is to begin the students in the studies on Epistemology and its objects, as well as to problematize the presence in the women in Epistemological researches. Since the scientific beginnings, who were the canons of Science? Where were they? Given these questions, the second moment is to present to the students some concerns about the silence of women in Epistemology.
\end{abstract}

Keywords: Silence ;Theory; Women.

\section{AS MULHERES E O CÂNONE OFICIAL DA FILOSOFIA}

"Eu cato papel, mas não gosto. Então eu penso: Faz de conta que eu estou sonhando". (Carolina Maria de Jesus)

A História das mulheres é sempre uma História de ausências e silenciamentos. Os processos históricos que as excluíram e os diferentes momentos em que foram consideradas bruxas também não auxiliaram os seus protagonismos. Na Filosofia, essa História não foi diferente. Encontramos nos livros uma breve referência a alguma ou outra, nunca com muita ênfase ou centralidade em suas pesquisas. 
Nos últimos dez anos, o interesse pelos estudos sobre filósofas se tornou crescente. É preciso um trabalho árduo para encontrarmos referências sobre suas vidas, suas pesquisas, seus trabalhos. O mais importante e o registro deste trabalho é que, ao contrário do que nos possa parecer a ausência é apenas aparente: as mulheres tentaram não ficar silenciadas. As mulheres, nas mais distintas épocas tentaram sim, fazer Filosofia e estudar Filosofia.

O marco deste trabalho é pensarmos como essas poucas mulheres conseguiram? Qual a força ou a coragem que nos permitiram ler os seus nomes ou estudá-las? Quais as barreiras enfrentadas por elas? O intuito é justamente as pensarmos no lugar que sempre estiveram e que poderiam estar? Quais os entraves que as barraram de também escrever a História? Por que as mulheres não puderam escrever a História da Filosofia e tudo que sabemos sobre elas foi escrito por homens?

Para Longini (2000), uma das hipóteses foi o pouco tempo que sobrou às mulheres, pois enquanto alimentavam a família e cuidavam sozinhas da casa e das crianças, os homens tinham todo o resto do tempo. Consoante com essa hipótese é a obra de Virginia Woolf (2004), denominada Um teto todo seu, pois para essa autora era exatamente esse o tempo que faltava às mulheres: além de não poderem sustentar a si, faltava um teto para olharem e poder pensar. Então, sobrou-nos pouco tempo para estudos, mesmo assim, algumas subverteram essas regras.

\section{UM POUCO DE FEMINISMO}

É difícil hoje pensarmos em uma definição unívoca do que seja o Feminismo e também pensarmos as barreiras históricas que esse Movimento já encontrou. Mas pensemos que, em um tempo, historicamente não muito distante, mulheres e homens viviam em situação de desigualdade gritante. Era comum e possível a violência física e psicológica contra as mulheres. Em contrapartida, na mesma medida em que mulheres eram tratadas como seres inferiores e sem voz, sempre houve mulheres que se rebelaram contra esse tratamento.

No âmago da luta pela igualdade de gêneros, cansadas dos abusos, surge o Movimento Feminista, lutando pela igualdade de direitos, pela possibilidade de que uma mulher tivesse exatamente as mesmas oportunidades que os homens, inclusive legalmente. Para Alves e Pitanguy (1981, p.8): "É difícil estabelecer uma definição precisa do que seja feminismo pois esse termo traduz todo um processo que tem raízes no passado, que se constrói no cotidiano." Poderíamos simplesmente pensarmos no feminismo com uma corrente que colocaria a mulher, ocupando a centralidade que o homem sempre ocupou. Essa seria uma definição simplista.

O Feminismo, enquanto Movimento foi um longo processo e "Como todo processo de transformação, contém contradições, avanços, recuos, medos e alegrias." (ALVES; PITANGUY, 1981, p.8). É possível pensarmos que muitas mulheres morreram de maneira injusta e, que se não houvesse o movimento, talvez muitos dos avanços e conquistas femininas jamais teriam existido. $O$ feminismo foi necessário para que as mulheres pudessem ter uma vida pública, trabalhar não só pela necessidade de sobrevivência, mas sobretudo para que pudessem ter as mesmas possibilidades e direitos que os homens.

É fato que, para as pessoas muito jovens, o feminismo pareça um movimento desnecessário, porém quando lembramos que o ingresso feminino no mercado de trabalho e o direito ao voto são conquistas do século passado, talvez possamos ter uma outra dimensão da luta feminista. $O$ enfrentamento não foi só para que as mulheres pudessem trabalhar e estudar, mas para que também pudessem ter direito a gerir seus próprios corpos e sua própria vida.

\section{UMA FILÓSOFA FEMINISTA}

Muitos estudos sobre a autora Simone Beauvoir são centrados exclusivamente no casamento vivido por ela e pelo também filósofo Jean Paul Sartre, em detrimento de seu vasto campo de exploração filosófica e até mesmo da escrita de suas quatro biografias. O que revelam seus 
trabalhos é que a filósofa jamais quis um casamento formal, o que para ela era sinônimo de representação e consolidação da moral burguesa. Viveu, portanto, com seu companheiro Sartre uma relação que durou cinquenta anos sem jamais dividir com ele o mesmo teto.

Uma relação considerada aberta, corroborando a tese de que Simone de Beauvoir viveu muito aquilo que escreveu e lutou: para ela o casamento burguês era, como tantas outras, uma forma de subordinação feminina. A histórica opressão feminina foi a principal luta da referida filósofa, luta essa que durou a sua vida inteira, traduzida na sua militância escrita, na participação em passeatas, nos relacionamentos que não couberam na moral da época, na adoção tardia de uma filha já adulta. A escrita de Beauvoir é a sua própria vida.

O estudo das histórias de vida tem desempenhado um papel importante nas pesquisas na área de Ciências Humanas. Por mais singular que uma história possa parecer, ela não está apartada da História oficial, podemos, através das histórias de vida, aprender sobre os costumes de uma época, regras, educação, cultura. Uma história de vida não se escreve sem o seu contexto, por isso a importância do uso de biografias, autobiografias e histórias de vida nos últimos anos.

As autobiografias de Beauvoir, por exemplo, fazem-nos pensar porque ela estudou tanto tempo. Era muito raro que uma moça estudasse tanto. Porém, é preciso entender que o fato de não haver existido um casamento tradicional e uma preparação para ele, possibilitou uma existência com um tempo maior dedicado aos estudos.

\section{IGUALDADE DE GÊNERO?}

Não é preciso estudar a História da Humanidade para repensarmos o papel feminino e sua finalidade. Os corpos e as mentes femininas sempre possuíram finalidades específicas, portanto a educação feminina teve como objetivo tornar as mulheres boas esposas e mães. A vida e a história das mulheres eram definidas no domínio da vida privada. As mulheres não possuíam vida pública.

Para isso as mulheres eram criadas e educadas, como se lhes houvesse um destino já traçado e esperado. Ao contrário do que se esperava de uma mulher de sua geração, Beauvoir (2016) subverte esse papel. Já não há um destino unívoco para as mulheres, uma vez que nem mesmo se nasce uma mulher. Entendemos, filosoficamente, como determinismo, um sistema pelo qual tudo aconteça devido a causas anteriores, de modo que aquilo que acontecer depois seja inevitável. Na Antiguidade, para Demócrito, eram as leis causais que determinavam o movimento dos átomos.

Segundo a autora, entretanto não há destino biológico, econômico ou psíquico que defina uma mulher. As mulheres, para ela não são seres passíveis de definição. Não há um único destino para uma mulher e nem para os seus corpos. Tese essa corroborada ainda, quando a autora afirma que é o conjunto da civilização que elabora esse produto intermediário entre o macho e o castrado (BEAUVOIR, 2016). Não há uma amarra a definir esse corpo e, ainda ele pode sofrer mudanças já que não há uma definição para ele. É como um corpo que, toma para si, o direito de ser aquilo que ele quiser.

Uma vez que o conjunto da civilização o defina, ele não é algo natural. Não se nasce, portanto como uma mulher, mas há um constructo social de saberes, determinantes históricos, econômicos e sociais que o definem desde o momento do nascimento. Para a autora Beauvouir (2016), ninguém nasce mulher. No nosso nascimento, não há determinismos nem garantias sobre a nossa sexualidade. Tese corroborada com a ideia de que não existe um destino biológico que nos defina ou determine.

Nos primeiros anos da infância, não há absolutamente nenhuma essência que diferencie meninas e meninos, ambos exploram o mundo da mesma maneira, aprendem com os mesmos estímulos e brincam com aquilo que está a sua disposição. O corpo, nesse primeiro momento, para a filósofa, nada mais é que a própria expressão da subjetividade. 
Para Cyfer (2015), é a cultura que define a experiência da mulher desse modo. É a partir da nossa vivência cultural, que se estabeleceram regras do que é ser homem e do que é ser mulher. Caso tivéssemos sido tratadas em condições de igualdade, historicamente também tivéssemos tido uma vida pública e os nossos direitos respeitados, talvez o rumo da História tivesse sido diferente. Foi a experiência social e cultural que nos definiu.

\section{A MULHER COMO O "O OUTRO"}

Historicamente, a mulher sempre foi vista como o "Outro". Não saiu para caçar, foi quem ficou cuidando a casa e os filhos. No mundo capitalista, a mulher "passa" a ser tratada como igual na força de trabalho, mas oprimida no salário. Embora cumprindo jornada de trabalho superior ou igual a dos homens, seus salários sempre foram inferiores.

Desde os primórdios, segundo Beavouir (2016), a mulher é vista como "O outro". É só na mediação de outrem que assim podemos considerar. Existe a alteridade porque existe a mediação, senão ela nem se configuraria possível.

Nessa perspectiva, Cyfer (2015) aponta que a mulher então é o Não-Sujeito, o Outro, o Segundo. Essa é uma das questões apontadas pela obra. Possivelmente, o próprio nome do título. O outro, que não ele mesmo. A ideia central é a de que, existe o segundo sexo porque obviamente existe o primeiro, a saber, o Masculino.

O interessante aqui, nessa perspectiva de alteridade é que, novamente ela não aparece como uma perspectiva da natureza. Há o segundo sexo, e ele é feminino, mas não naturalmente construída essa ideia.

Importante ressaltar que nem sempre essas ideias foram interpretadas nesta perspectiva. A recepção da obra O segundo sexo não foi tranquilo para a autora. Segundo Cyfer (2015), Simone recebeu acusações de "neurótica", "frustrada", "mulher-macho". Em um tempo em que muitos liam manuais sobre como uma boa esposa deveria se portar ou investiam em casamentos prematuros para mulheres, é compreensível entendermos que a obra tenha causado estranhamento. Por que uma mulher estava tão irritada com o modelo instituído?

Sobre a mulher como a alteridade, Pacheco (2015), afirma que a questão da diferença envolve uma relação hierárquica. Para a autora, o propósito é colocar a mulher como o "outro", o "desviante", o "diferente". Isso fica claro quando se adota o termo "Homem" para designar a universalidade. O Homem é o sinônimo de universal, de igual para todos na Ciência. Homem é o que caracteriza a todos como humanos e a palavra Homem foi atribuída uma caracterização que valha para todos e todas.

A aparente neutralidade não é ingênua, corrobora linguisticamente com a forma de pensar e ver o mundo. Os filósofos todos escreveram dessa maneira e nenhum incomodou-se de usar a palavra Homem também para se referir às mulheres, já que a palavra garantiria um caráter de universalidade. Serviu para fortalecer uma relação de poder e desigual existente entre homens e mulheres que, em alguma medida, perdura até hoje.

\section{TEORIA FEMINISTA E ENSINO DE FILOSOFIA}

Mesmo que o ingresso das mulheres no mercado de trabalho e na educação formal seja recente, elas tentaram. Estiveram presentes em diferentes países, em diferentes culturas, atentando para o seu lugar, para as suas questões de gênero, para a sua História. A partir do século XIX, alguns autores contemporâneos começaram a questionar uma espécie de crise da razão instrumental. Os cânones que até então eram inabaláveis, passam a ser contestados, assim como a razão, quando esses autores e alguns seguidores passam a problematizar a ideia de que todo o conhecimento é parcial e provisório.

O conhecimento passa, então, a ser algo que não fica confinado a gabinetes e nem o cientista é alguém neutro e que não coloca nenhuma intencionalidade na pesquisa que desen- 
volve. A Ciência, já não mais é uma derivação da Ciência Moderna, muitos cânones e preceitos oriundos dessa tradição passam a ser questionados.

É nesse contexto que se desenvolve a perspectiva de uma Epistemologia Feminista, na visão das mulheres, como a Epistemologia se desenvolve? De que forma posso pensar em uma Epistemologia Feminista? Qual o caminho que devo seguir? Não há distinções entre a Epistemologia tradicional e a Epistemologia Feminista?

A Epistemologia ou a Teoria do Conhecimento é o campo de estudos que se ocupa das relações entre Sujeito e Objeto no ato de conhecer. Para os gregos, Ciência significava Episteme e seu oposto era a doxa, que significava a opinião, a qual poderia ser algo subjetivo, pois cada um possuía a sua. Essas relações foram mudando ao longo do processo Histórico. Para alguns autores, havia uma espécie de neutralidade do Sujeito e, portanto, era o objeto que delineava o que era possível conhecer. Para outros, o Sujeito se colocava todo o tempo no conhecimento e delimitava as possibilidades/limites do conhecimento.

Desde os Pré-Socráticos, já havia uma interrogação sobre aquilo que o homem deveria conhecer. A partir de Sócrates, essa preocupação se torna antropológica. Sócrates se volta a questões ligadas ao Homem. Temos poucos relatos, nesse período, sobre a participação das mulheres nos estudos filosóficos.

Então, nesse princípio de investigação Epistemológica, temos pouco conhecimento sobre a presença feminina na Filosofia. Sabemos, brevemente sobre a presença de Themistocleia e Safos de Lesbos, porém, pouco há sobre elas na História da Filosofia Antiga. Há, ainda, a possibilidade de muitas outras terem estudado Filosofia, mas suas vozes e escritos não chegaram até nós. Para Berquó (2016, p.29): "Quando se estuda sobre as mulheres da Grécia do período clássico (V-IV a.C.) o principal obstáculo é o fato de que os documentos disponíveis foram quase todos feitos por homens."

E nos séculos seguintes, com a Filosofia Medieval, a Patrística, a Escolástica, seja nos estudos de Santo Agostinho ou de são Tomás, a História da Filosofia está relacionada à religião. Importante ressaltar que, em qualquer dos momentos históricos, a Epistemologia ocupou um lugar central na Filosofia.

Havia mulheres estudando Filosofia? Sim, porém continuaram ocupando um lugar secundário, ainda não escrevendo a sua própria História. Na ldade Moderna, inverte-se o polo de atenção. O sujeito passa a ser o Sujeito Moderno, é ele quem constrói o conhecimento e delimita os parâmetros daquilo que deve ser conhecido. Há uma disputa clássica entre Empiristas e Racionalistas sobre o conhecimento.

Mais tarde, Kant é uma espécie de mediador: o conhecimento começa, sim, nos sentidos, mas é a razão que vai corroborar o conhecimento, portanto Kant funciona como uma espécie de mediador entre Racionalistas e Empiristas. $O$ cerne da questão então, quando estudamos Epistemologia enquanto área na disciplina de Filosofia é conseguirmos fazer a relação entre o conhecimento e o Sujeito Cognoscente. Epistemologia é tudo o que envolve o conhecimento, as formas de conhecer, as suas possibilidades e limitações. Essas foram as preocupações modernas sobre o saber/conhecimento científico. Para Ketzer (2017, p.95): "Ela é uma área central para qualquer campo do conhecimento que busque fundamentar seus métodos e justificá-los."

A Epistemologia acabou sendo parâmetro para diversas áreas do conhecimento, pois a partir dela estabeleceu-se uma teoria sobre o todas as questões concernentes ao campo do conhecimento, aos seus processos, quem conheceria, etc. Ela é um marco, pois além de haver uma prática científica, existia pessoas se debruçando sobre a teoria. Foi a Epistemologia que se ocupou, ao longo da História, em responder questões sobre o conhecimento: como é o conhecimento? O que conhecemos? O que devemos e como podemos conhecer? Esse é o legado da Epistemologia à História. As preocupações concernentes ao conhecimento estavam contidas nas discussões dessa área. 
Conhecimento possui gênero? Qual seria? Para Longino (2000, p.513): "Como o conhecimento adquiriu gênero e como pode ser desprovido dele?" Em qual momento histórico nos foi colocado que o conhecimento deveria ter um gênero e esse gênero seria o masculino? Essas questões são parte daquilo que devemos colocar em contestação quando nos dispomos a estudar Epistemologia. Como devemos pensar nos conceitos clássicos como objetividade e neutralidade no feminino? Essa tarefa, por si só, já nos fomenta um exercício singular.

A possibilidade de uma Epistemologia feita por mulheres não é algo recente, já que, desde o início da Filosofia, também as mulheres tentaram fazer Ciência. Recentemente, alguns autores passaram a se preocupar com essa invisibilidade feminina. Para Calvelli; Lopes (2011, p.346): "As formulações dos 'filósofos da diferença' como Foucault, Deleuze, Lyotard, Derrida, entre outros como são denominados, convergem na mesma direção que a crítica feminista." Para esses autores, há pontos muito precisos na Epistemologia que já deveriam há muitos anos ter sido questionados. Por exemplo, porque a Ciência sempre possuiu um caráter ideológico, particularista, racista?

Conforme Castro; Egger (2012,p.252): "Evidentemente o poder de contar a história e escrevê-la ficou como tarefa dos homens, e, aqui, não nos referimos a todos os homens, mas a um padrão normativo androcêntrico." Não resta dúvidas de que, a História da Ciência foi contada por homens, mas não homens que viviam em condições quaisquer. A História da Ciência foi realizada por homens brancos, que seguiam um determinado padrão.

A Teoria Feminista e os filósofos da diferença questionam esses parâmetros. Por mais que tenham existido mulheres na Filosofia, por que temos tanta dificuldade em encontrá-las? O sujeito do conhecimento, a partir dos pensadores citados, passam a ser colocados em um contexto amplo. Não cabe a descontextualização, os estereótipos de sempre. A questão é pensarmos que todos e todas podem e devem fazer Ciência. Para Calvelli; Lopes (201 1, p. 348): "A teoria feminista e os "filósofos da diferença'" chamam a atenção para o fato de que o sujeito do conhecimento deve ser considerado como efeito das determinações culturais."

Essa é a grande contribuição, pois não importa a sexualidade, a cor ou a classe social de quem faz Ciência. Tampouco faz sentido ser homem ou mulher. Ciência é Ciência e se a Epistemologia até agora não fez esses questionamentos, agora já estamos em tempo. Ela abrange um campo de conhecimento maior, pois agrega à racionalidade também saberes experenciais, discussões sobre heteronormatividade, sexualidades e conjuga saberes até então desprezados pelos parâmetros científicos.

A necessidade de um estudo sobre a Epistemologia Feminista também tangencia a emergência de pensarmos na ausência das mulheres nos estudos de Filosofia. Não podemos simplesmente nos conformarmos com o fato de que elas sempre representaram um menor número de estudiosas e, por esse simples fato, quase não as estudamos. Para Longino (2000, p.506): "A experiência das mulheres torna-se invisível e distorcida, assim como as relações de gênero. Que razão temos para acreditar que a filosofia e suas subdisciplinas podem estar imunes?"

A ausência ou o simples silenciamento das mulheres não pode ser motivo de conformidade. Essa deve ser a interrogação filosófica, o lugar do gênero na Filosofia também. É nesse contexto que entendemos a necessidade de uma Filosofia feminista, pois em outras áreas do conhecimento também questiona-se a necessidade da participação feminina.

\section{CONSIDERAÇÕES FINAIS}

Desde os primórdios da Filosofia temos conhecimento de Filósofas como Safos de Lesbos e Themistocleia, mais tarde Hildegard e outras filósofas, apesar de que dificilmente lemos qualquer uma delas nas Histórias da Filosofia tradicionais. É difícil que alunos e alunas do atual Ensino Médio encontrem referências em seus livros didáticos ou em suas apostilas de cursinhos preparatórios para o ENEM.

Ensiná-los, desde a Educação Básica que sempre houve mulheres interessadas em estudar 
Filosofia é tarefa de todos nós. Acreditar que as mulheres talvez não apareçam ao longo da História porque não tiveram as mesmas chances, pois a ampliação de sua participação na vida pública apenas começou a acontecer a partir do século passado, deveria fazer parte dos currículos.

O que vale, no ensino de Filosofia, sempre é inquietação. Não foi objetivo deste trabalho prescrever uma fórmula de como os professores e professoras da educação básica deveriam elaborar as suas aulas a partir de uma Epistemologia feminista, o mais importante é pensarmos o lugar da mulher na História e, se vamos ou não ter a ousadia de repensar junto aos alunos.

Não podemos olhar a História da Ciência e lamentar o que foi feito ou não sobre a História das mulheres, mas podemos pensar, a partir de agora, como podemos repensar a Epistemologia em uma perspectiva em que as mulheres não fiquem excluídas.

A tarefa não é simples, pois implica a nós educadores, buscar fontes, livros, textos, artigos, aos quais nem sempre temos acesso em nossas escolas, sobretudo quando trabalhamos em escolas afastadas dos centros das cidades.

\section{REFERÊNCIAS:}

ALVES, P.M; PITANGUY, J. O que é feminismo. São Paulo: Brasiliense/ Abril Cultural, 1981.

BEAUVOIR, Simone. de. O segundo sexo. São Paulo: Editora Nova Fronteira, 2016.

BERQUÓ, Thirzá Amaral. Aspásia de Mileto: Mulher e Filosofia na Atenas Clássica I. In: PACHECO, Juliana (Org.). Filósofas: a presença das mulheres na filosofia. Porto Alegre, RS: Editora Fi, 2016, pp. 28-43.

CALADO, E.A.F. Autobiografias de Simone Beauvoir: Sujeito, Identidade, Alteridade. Tese de Doutorado/Unb,2012.

CALVELLI, Haudrey Germiniani; LOPES, Maria de Fátima (2011). A teoria do conhecimento e a epistemologia feminista. In Livro de Anais do Congresso Scientiarum Historia IV, p. 347-353. Acesso em 22 de julho de 2013 de www.hcte.ufrj.br/downloads/sh/sh4/trabalhos/Haudrey.pdf.

CASTRO, A. M. A; EGGERT, E. Alguns apontamentos sobre a epistemologia feminista. Revista Sociais e Humanas, [S.I.], v. 25, n. 2, p. 231-238, dez. 2012. Disponível em: https://periodicos.ufsm.br/sociaisehumanas/article/view/2862. Acesso em: 29 jun. 2018.

CYFER. Afinal, o que é uma mulher? Simone Beauvoir e a Questão do Sujeito na Teoria Crítica Feminista. Disponível em: http://www.scielo.br/pdf/In/n94/0102-6445-In-94-00041.pdf. Acesso em $24 / 04 / 2018$

HAUDREY, G. C.; LOPES,M.de F. A teoria do conhecimento e a Epistemologia Feminista. UFRJ: Livro de Anais do congresso Scientiarum, 2011.

PACHECO, J. (Org). Filósofas: a presença das Mulheres na Filosofia. Porto Alegre: Editora Fi, 2016.

KETZER,P.Comopensaruma Epistemologia Feminista? Surgimento, Repercussõese Problematizações. In: Revista de Filosofia Argumentos. Fortaleza: 2017.

LONGINO, H. E. Epistemologia Feminista. In: GRECO, J. SOSA, E. (Org.) Compêndio de Epistemologia. São Paulo: Edições Loyola, 2000.

MACIEL, W. Substantivismo, determinismo e o debate acerca do estatuto ontológico do 
espaço-tempo. Principia (UFSC), v. 11, p. 427-436, 2012.

PACHECO, J.(Org). Onde estão as Filósofas na Filosofia? In: Mulher e Filosofia: as relações de gênero no pensamento filosófico. Porto Alegre: EDIPUCRS, 2015.

WOLF, V. Um teto todo seu. Trad. Vera Ribeiro. Rio de Janeiro: Nova Fronteira, 2004. 